\title{
Alzheimer's Disease and Metals: A Review of the Involvement of Cellular Membrane Receptors in Metallosignalling
}

\author{
Pavithra C. Amadoruge ${ }^{1,2}$ and Kevin J. Barnham ${ }^{1,2}$ \\ ${ }^{1}$ Bio21 Molecular Science and Biotechnology Institute, The University of Melbourne, 30 Flemington Road, Parkville, \\ VIC 3010, Australia \\ ${ }^{2}$ Department of Pathology, The University of Melbourne, and The Mental Health Research Institute, Parkville, VIC 3052, Australia
}

Correspondence should be addressed to Kevin J. Barnham, kbarnham@unimelb.edu.au

Received 15 October 2010; Accepted 5 January 2011

Academic Editor: Paolo Zatta

Copyright ( $) 2011$ P. C. Amadoruge and K. J. Barnham. This is an open access article distributed under the Creative Commons Attribution License, which permits unrestricted use, distribution, and reproduction in any medium, provided the original work is properly cited.

\begin{abstract}
Alzheimer's disease $(\mathrm{AD})$ is a debilitating form of dementia. The hallmark protein associated with the disease is the amyloid beta $(\mathrm{A} \beta)$ peptide. Aggregation of $\mathrm{A} \beta$ has been shown to depend on interactions with metals. The recent studies now demonstrate that metals also play additional important roles in the disease process. Consequently, there may be benefit from modulating metal homeostasis. However, the role and subcellular location of metals within neurons is not well understood. There is growing evidence to suggest that metals can act at the site of cellular membrane receptors and affect cellular signaling by modulating the signal transduction of those receptors. The glutamatergic and cholinergic receptor systems, both well-known neurotransmitter systems affected in $\mathrm{AD}$, have well-documented metal interactions, as do the tropomyosin-receptor kinase (Trk) family of receptors and the epidermal growth factor (EGF) receptor. In this paper, the metal interactions with these membrane receptor systems will be explored and thus the potential for membrane receptors as an intervention point in $\mathrm{AD}$ will be assessed.
\end{abstract}

\section{Introduction}

Alzheimer's disease (AD) is the most common form of agerelated dementia $[1,2]$. The key neuropathological features include extracellular amyloid beta (senile) plaques $(\mathrm{A} \beta)$, intracellular neurofibrillary tangles, chronic oxidative stress, and disease progression leading to cognitive decline and eventually neuronal cell loss $[1,2]$. The cognitive decline observed in $\mathrm{AD}$ has its roots at the synapse, the space between neurons, through which they communicate. The synapse is also the site at which the $\mathrm{A} \beta$ peptide, the characteristic amyloid protein associated with $\mathrm{AD}$, is believed to first deposit [2]. It is also the site where $\mathrm{A} \beta$ may interact with metals released as a consequence of glutamatergic transmission. In the recent years, growing evidence points to soluble $\mathrm{A} \beta$ oligomers being the toxic species [3] and whose appearance correlates with disease progression $[4,5]$. It has also been hypothesized that small oligomers as opposed to $\mathrm{A} \beta$ fibrils induce synaptic failure [6,7], after experiments showed $A \beta$ oligomers to inhibit long-term potentiation
(LTP) [8-10], a biochemical model of synaptic strength [11]. Furthermore, early memory loss associated with the disease has been attributed to synapse loss occurring prior to neuronal cell death $[6,7]$, and there are reports of a decrease in synaptic protein levels in $\mathrm{AD}$ [12].

\section{Metals, Aging, and Alzheimer's Disease}

The ability of life to utilize oxygen is dependent on the chemistry of transition metal ions. Metal ions are able to coordinate $\mathrm{O}_{2}$ enabling transport, and the ability of transition metal ions to move between various oxidation states allows the activation and ultimately utilization of oxygen. If not properly regulated the same chemistry that allows the transport and utilization of oxygen can have the potential to generate reactive oxygen species (ROS). Metals are integral for the function of enzymes and numerous intracellular signaling proteins, and in a healthy individual, the levels of these metals are highly regulated. With normal 
aging and more so in a neurodegenerative disease state, such homeostatic mechanisms are postulated to become perturbed, leading to aberrant metal-dependant enzyme function, mitochondrial dysfunction, and the production of ROS, all of which are well-known aetiologies associated with AD.

The transition metals implicated in $\mathrm{AD}$ include copper $(\mathrm{Cu})$, zinc $(\mathrm{Zn})$, and iron $(\mathrm{Fe})$ [13]. These metals are generally found ligand-bound, and not as free ions. Although there do exist pools of metal that are coordinated to lower affinity ligands and as such are readily exchangeable. There is increasing evidence to suggest that $\mathrm{Cu}$ and $\mathrm{Zn}$ may exist as free ions when released into the synapse as part of the synaptic transmission process (reviewed in [1]). These metals can reach up to micromolar levels in the synaptic cleft [1], with $\mathrm{Cu}$ reaching $15 \mu \mathrm{M}$ but $\mathrm{Zn}$ reaching up to $300 \mu \mathrm{M}$ in the mossy fibres of the hippocampus postaction potential input $[1,14]$.

Aging is the main risk factor associated with all neurodegenerative diseases. Metal dyshomeostasis is an important feature of $\mathrm{AD}$ and this may be related to aging. There is an apparent state of intracellular $\mathrm{Cu}$ deficiency and an extracellular increase in $\mathrm{Cu}$ and $\mathrm{Zn}$, possibly due to the metals binding to $\mathrm{A} \beta$ (reviewed in [1]). Binding of metals to $\mathrm{A} \beta$ can promote aggregation of the peptide with pathological consequences [15].

In the case of $\mathrm{AD}$, the most common form of age-related dementia [16, 17], a state of $\mathrm{Cu}$ imbalance, can also lead to a dysfunction of vital cuproenzymes such as cytochrome c oxidase (COX) of the electron transport chain, as well as antioxidants such as superoxide dismutase (SOD1), resulting in oxidative stress via the generation of reactive oxygen species (ROS). Fe levels are also increased in the neuropil of the AD brain [13] and can contribute to the production of ROS and oxidative stress. Oxidative stress can ultimately result in neuronal cell dysfunction, which can lead to a lack of synaptic transmission.

There is growing evidence that suggests metals are able to act on receptors at the cell membrane with the hypothesis being that altered metal homeostasis affects cell signaling due to outside-in signal transduction. In this paper, known metal interactions with relevant membrane receptors will be discussed and potential therapeutic implications to AD will be assessed.

\section{The Glutamatergic System and AD}

The major neurotransmitter at excitatory synapses in the brain is glutamate. The glutamatergic system of synaptic transmission contains ionotropic and metabotropic glutamate receptors, with the latter lacking a channel for ion flux but instead glutamate binding induces a change in the intracellular domain of the receptor, allowing for intracellular signaling. Failure in glutamatergic transmission is common in most neurodegenerative diseases, including $\mathrm{AD}[18]$.

The ionotropic glutamate receptors are divided into $\mathrm{N}$-methyl-D-aspartate (NMDA) and non-NMDA receptors with both receptor classes allowing the flux of ions whereby an electrical signal is translated into a chemical signal. The non-NMDA receptors (non-NMDARs) are $\alpha$-amino3-hydroxy-5-methyl-4-isoxazole propionate (AMPA) and kainate receptors, with AMPA receptors (AMPARs) being responsible for fast and transient synaptic transmission. The role of the kainate family of ionotropic receptors is less well understood however they are present preand post-synaptically and maybe involved in neuron-glia signaling [19], as well as being involved in the modulation of synaptic transmission and plasticity [20]. Activation of NMDARs by presynaptically released glutamate causes calcium $\left(\mathrm{Ca}^{2+}\right)$ entry which activates the $\mathrm{Ca}^{2+}$ dependant kinase, $\mathrm{Ca}^{2+} /$ calmodulin dependent-protein kinase II (CaMKII) [21]. The activated CaMKII associates with the NMDAR, leading to AMPAR phosphorylation [21-23]. This event encourages greater channel conductance of the AMPAR, and more importantly AMPAR insertion upon an LTP-inducing stimulus $[21,24,25]$. Soluble A $\beta$ oligomers bind to NMDAR in AD [26] and induce NMDAR internalization [27]. There is further work indicating that binding of CaMKII to the NMDAR channel is required for LTP induction [28].

NMDARs are reported to interact directly with a suite of intracellular proteins, adhesion and signaling molecules, such as CaMKII, neuronal nitric oxide synthase (nNOS), and F-actin (see [29]) and indirectly influence the activation of cAMP response element-binding (CREB) and brain-derived neurotrophic factor (BDNF) (see [30]) as well as intracellular kinases such as extracellular signal regulated kinase (ERK), glycogen synthase kinase 3 (GSK3), and Akt.

There is evidence to suggest that the NMDAR interacts with amyloid peptides and their precursor proteins. For example, patch clamp recordings of primary hippocampal cultures from APP KO mice showed increased NMDARmediated EPSCs [31]. A $\beta$ has both direct and indirect interactions with the receptor. It is postulated, as described earlier, that small oligomeric species are the key toxic elements in numerous amyloid diseases, such as AD [3]. These species have been shown to colocalize with the NR2B NMDAR subunit in rat hippocampal slices [32]. These species, as well as the $\mathrm{A} \beta$ peptide itself, interact with the NMDAR and can induce an increase in intracellular $\mathrm{Ca}^{2+}$. This in turn leads to membrane permeabilisation, a common phenomena when amyloid proteins interact with the cell membrane [33-36]. A $\beta$ can also propagate the loss of NMDARs from the cell surface [37]. A loss of NMDARs from the synapse has been found in $\operatorname{AD}$ brains $[38,39]$. Hoey et al. also recently reported that activation of synaptic NMDARs promoted $\alpha$-secretase mediated APP processing and inhibited $A \beta$ production in mouse primary cortical neurons [40].

It has been shown that different $\mathrm{A} \beta$ oligomers can exert different affects. In in vitro studies looking at the dentate gyrus, $A \beta 1-40$ was found to selectively increase NMDARmediated transmission, whereas $\mathrm{A} \beta 1-42$ has been shown to reduce NMDAR-mediated synaptic currents in the dentate gyrus $[41,42]$. Thus it is apparent that $\mathrm{A} \beta$ is able to influence glutamatergic transmission via the NMDAR. 
Due to the implication of NMDARs in neurodegenerative diseases, and especially $\mathrm{AD}$, drugs that exploit the properties of the receptor have been developed as potential therapeutics for the disease. Excitotoxicity, caused by overstimulation of NMDARs due to excessive glutamate release, is a common cause of neuronal loss in most neurological insults including stroke as well as neurodegenerative diseases, such as $\mathrm{AD}$ [43]. As a result, NMDAR antagonists have become attractive therapeutics for the potential treatment of these diseases with memantine being utilized clinically, to treat AD patients.

\section{The Glutamatergic System and Metals}

The most extensive work done examining the glutamatergic system and transition metals is via study of the NMDAR and its metal interactions. Metals, especially $\mathrm{Cu}$ and $\mathrm{Zn}$, have been shown to have a modulatory effect on NMDAR function within the glutamatergic system.

$\mathrm{Zn}$ is coreleased along with glutamate into the glutamatergic synapse [44-46], thus its role in signaling within the brain may best be assessed in its role as a neurotransmitter. It is well documented that the NMDAR possesses an inhibitory Zn binding site on the NR2 subunit [47-50]. The equilibrium dissociation constant $\left(K_{d}\right)$ of $\mathrm{Zn}$ for the NMDAR was reported to be $13 \mu \mathrm{M}$ [51] but almost a decade later extracellular $\mathrm{Zn}$ concentrations as low as $3 \mathrm{nM}$ were shown to be inhibitory of NR1-NR2A containing receptors [50]. $\mathrm{Zn}$ inhibits the NMDAR in both a voltage-dependent and independent manner with the affinity being higher in the latter, inferring that $\mathrm{Zn}$ binds at a different site on the receptor to the voltage-dependent magnesium $(\mathrm{Mg})$ channel blocking site. Also, the $\mathrm{IC}_{50}$ of the voltage-independent $\mathrm{Zn}$ inhibition is 50 -fold lower in NR1-NR2A containing receptors than NR1-NR2B containing receptors [50]. Zn released from excitatory synapses in the hippocampus inhibits NMDARs [52, 53]. Furthermore, synaptic $\mathrm{Zn}$ entry via glutamate receptors into neurons in the CA3 region of the hippocampus evokes LTP [54]. Interestingly, in the CA1 region of the rat hippocampus, synapses containing presynaptic vesicular Zn showed a decrease in postsynaptic AMPAR subunit levels whilst NMDAR levels were unchanged [55]. This implies that vesicular $\mathrm{Zn}$ could confer the behavior of a synapse during synaptic transmission, further cementing the modulatory role that $\mathrm{Zn}$ plays at the glutamatergic synapse.

A known interaction of the NMDAR with metals, is the role it plays in $\mathrm{Cu}$ homeostasis within the cell. Schlief and Gitlin have developed a model based on experiments in mouse hippocampal neurons [56]. Upon NMDAR activation by glutamate, $\mathrm{Ca}^{2+}$ enters into the cell, as previously discussed. This increase in $\mathrm{Ca}^{2+}$ within the cell having activated an intracellular signaling cascade induces the Menkes ATPase protein to translocate to a membrane bound compartment to generate and replenish a readily releasable pool of $\mathrm{Cu}$. An increase in $\mathrm{Ca}^{2+}$ as a result of NMDAR activation can act upon this novel pool and cause the extracellular release of $\mathrm{Cu}$. This released free $\mathrm{Cu}$ can then act back upon the NMDAR in a functionally negative feedback fashion, to inhibit $\mathrm{Ca}^{2+}$ flux and inhibit further $\mathrm{Cu}$ release. The Menkes ATPase protein is required for $\mathrm{Cu}$ efflux [56], and translocation of the protein as a result of NMDAR activation creates a link between NMDAR activation and $\mathrm{Cu}$ homeostasis.

Further work from Schlief et al. demonstrated that $\mathrm{Cu}$ treatment of hippocampal neurons showed a decrease in the elevation of intracellular $\mathrm{Ca}^{2+}$, without affecting the localization or distribution of NMDARs, suggesting that $\mathrm{Cu}$ has a direct effect on NMDAR function [57]. $\mathrm{As}^{2+}$ is a potent electron acceptor, it can potentially catalyze $\mathrm{S}$ nitrosylation of NMDARs, resulting in a loss of secretable $\mathrm{Cu}$ as in the case of Menkes Disease. This then leaves the cell deficient in controlling NMDAR activation which may lead to an increase in $\mathrm{Ca}^{2+}$ [56]. LTP studies on the CA1 region of rat hippocampus showed reduced EPSCs by low micromolar $\mathrm{Cu}$ concentrations [56].

$\mathrm{Cu}$ is released post-synaptically $[58,59]$ where as $\mathrm{Zn}$ is believed to be co-released with glutamate, presynaptically, into the synaptic cleft [60]. Cu and $\mathrm{Zn}$ can reach micromolar concentrations within the synaptic cleft (see above) as compared to glutamate which can reach low millimolar concentrations after excitatory synaptic transmission [56].

These data taken together suggest that metals play an important role in modulating NMDAR function.

\section{The Cholinergic System and AD}

Acetylcholine (ACh) is a neurotransmitter, which is important in learning and memory networks $[61,62]$. Cholinergic receptors are receptors that respond to ACh. Cholinergic receptors are divided into two categories, depending on their exogenous agonists. This includes nicotinic receptors (nAChR) whose exogenous agonist is nicotine, and muscarinic receptors (mAChR) whose exogenous agonist is muscarine. Both nAChRs and mAChRs are found in the central nervous system and in the periphery; however the neuronal subclasses of each receptor type will be discussed in this paper.

Along with hallmark pathologies associated with $\mathrm{AD}$ for example, presence of high levels of $\mathrm{A} \beta$, there are also known deficits in the cholinergic system in the AD brain [63-65]. Brain regions highly affected in $\mathrm{AD}$, as the neocortex and the hippocampus have significant changes to their cholinergic innervation [64]. There are several reports of a loss of cholinergic fibers and terminals in $\mathrm{AD}$, as well as reductions in cholinergic receptors $[64,66,67]$. The activities of the two major cholinergic enzymes, choline acetyltransferase (ChAT) and acetylcholinesterase (AChE), are reported to be decreased in $\mathrm{AD}$ [68-70]. Reductions in ChAT activity are the greatest $[71,72]$ and correlate with disease severity $[68,73]$.

The basal forebrain is where the origins of the cholinergic neurons innervating the cortex lie. It is widely reported that there is a loss of these cholinergic basal forebrain neurons in the $\mathrm{AD}$ brain $[69,74,75]$. There is uncertainty however, if this neuron loss occurs as result of $\mathrm{A} \beta$ toxicity on the cortical cholinergic terminals causing retrograde degeneration, or if the loss of cholinergic basal forebrain neurons is a primary consequence of $A \beta$ toxicity, with the loss of cortical cholinergic innervation being a secondary 
consequence. Numerous transgenic mouse models and cell lines have been used to attempt to delineate this. In aged APP23 mice, there was a significant decrease in cortical cholinergic fiber length but no loss of cholinergic basal forebrain neurons when compared with aged-matched wildtype neurons suggesting that deficit of cortical cholinergic innervation in these mice is a local effect of $\mathrm{A} \beta$ which is not caused by deficit of cholinergic basal forebrain neurons [72]. A significant decrease in ChAT activity in the tissue of APP23 mice with no significant effect on AChE levels, when compared with aged-matched wild-type mice was shown. Similar results were reported by Pedersen et al. where a decrease in the activity of ChAT was observed with no effect on AChE activity in SN56 cells, a mouse cell line derived from basal forebrain cholinergic neurons [71]. They also showed $\mathrm{A} \beta 1-42$ suppressed the synthesis of $\mathrm{ACh}$ in a nontoxic manner with this reduction being prevented by cotreatment with all-trans-retinoic acid, a compound formerly shown to increase mRNA expression of ChAT in these cells [71], indicating that $\mathrm{A} \beta$ can have non toxic effects on the basal forebrain cholinergic neurons.

$\mathrm{A} \beta$ has also been shown to bind to neuronal $\alpha 7$ nicotinic $\mathrm{ACh}(\alpha 7 \mathrm{nACh})$ receptors with high affinity $[76,77]$ which can cause a suite of toxic consequences. As previously discussed $\mathrm{A} \beta$ binding to the NMDAR can cause internalization of the NMDAR and inhibit LTP. Snyder et al. reported $\alpha$-bungarotoxin, a specific $\alpha 7 \mathrm{nACh}$ antagonist, to reduce $A \beta$-induced NMDAR internalization, suggesting that NMDAR function may be negatively affected by an $\mathrm{A} \beta$ $\alpha 7 \mathrm{nACh}$ interaction [27]. Wang et al. recently showed in synaptosomes prepared from both $\mathrm{AD}$ postmortem tissue as well as frontal cortex slices from postmortem tissue exposed to $\mathrm{A} \beta 1-42$ that S 24795 , a partial $\alpha 7 \mathrm{nACh}$ agonist, can release $A \beta$ from the $A \beta-\alpha 7 \mathrm{nACh}$ complex allowing for partial recovery of function of the $\alpha 7 \mathrm{nACh}$ and the NMDAR [78]. This demonstrated that disruption of the $\mathrm{A} \beta-\alpha 7 \mathrm{nACh}$ interaction may be a mean of reducing pathophysiological features of $\mathrm{AD}$.

\section{The Cholinergic System and Metals}

There are a few reports of lead $(\mathrm{Pb})$, aluminium $(\mathrm{Al})$, and cadmium (Cd) having an effect on the cholinergic system in vitro and in vivo [79-81].

As $\mathrm{Pb}$ exposure can produce poor learning and deficits in intelligence tests [82], the interaction of $\mathrm{Pb}$ with the cholinergic system has been studied extensively as a mean of discovering the mechanism of toxicity of $\mathrm{Pb}$ in the brain which causes these neurological effects.

There are conflicting reports, however, on the affect of $\mathrm{Pb}$ on the cholinergic system. Moingeon et al. reported that an acute in vivo treatment of rats with the metal inhibits ACh turnover, decreases ACh content in certain brain regions, and induces a reversible increase in mAChRs in the striatum and cortex [83]. However, this latter finding is refuted by Schulte et al., where they had found there to be no major effect of $\mathrm{Pb}$ on $\mathrm{mAChRs}$ in the frontal cortex of mouse brain [84]. This finding was supported by Gotti et al., using an in vitro model of both differentiated and undifferentiated cholinergic neurons [85]. They also found that $\mathrm{Pb}$ increased the number of nAChR binding sites, although Costa and Fox had reported that chronic $\mathrm{Pb}$ exposure to decrease mAChRs in the visual cortex alone of neonatal rats [79]. It is apparent that the effect that $\mathrm{Pb}$ has on the cholinergic system is very much dependant on the type of cholinergic receptor studied.

$\mathrm{Al}$ increased the number of mAChRs in cholinergically differentiated IMR32 cells, a human neuroblastoma cell line, whereas it had no effect on nAChRs, as measured by $\alpha$-bungarotoxin binding sites [85]. However Johnson and Jope reported $\mathrm{Al}$ reduced the effects of an in vitro $\mathrm{ACh}$ agonist, carbachol [80]. In the same paper, $\mathrm{Cd}$ increased both the $\mathrm{mAChR}$ and $\mathrm{nAChR}$ expressions in cholinergically differentiated and undifferentiated IMR32 cells.

As discussed, there are few studies investigating the role of cholinergic receptors and metals, and of those that do, few give conclusive outcomes and did not investigate other metals associated with $\mathrm{AD}$ pathology such as $\mathrm{Cu}$ and $\mathrm{Zn}$. As a result, more work is required to determine if metals could play a role in mediating the cholinergic deficits associated with AD.

\section{TrkB Receptors and AD}

Tropomyosin-receptor kinase (Trk) receptors are necessary for the survival, differentiation, and maturation of the developing brain [86]. Trk receptors have been shown to play a role in synaptic plasticity as well as in modulating synaptic transmission $[87,88]$. Furthermore a Trk receptor family variant, the $\operatorname{TrkB}$ receptor, has been reported to be important for LTP in CA1 neurons $[89,90]$. The endogenous agonists for $\mathrm{TrkB}$ receptors are brain-derived neurotrophic factor (BDNF) and neurotrophin-4/5 (NT-4/5), with BDNF being specific for TrkB receptors [91].

TrkB activation was traditionally believed to be via neurotrophin binding, inducing $\operatorname{TrkB}$ receptor dimerisation leading to phosphorylation of the cytoplasmic tyrosine kinase tails. This mediates an elaborate signaling cascade ultimately resulting in antiapoptotic outcomes [91, 92]. However Lee et al., showed that TrkB signaling can occur independently of neurotrophin binding, through what is known as "transactivation" by G protein-coupled receptor (GPCR) ligands for example, adenosine and PACAP. Followup studies revealed the role of Src kinase-tyrosine phosphorylation in intracellularly activating cell membrane and intracellular TrkB receptors [93, 94].

There are reports of the $\operatorname{TrkB}$ receptor-BDNF pathway being compromised in $\mathrm{AD}$. In the hippocampus of $\mathrm{AD}$ patients, a decrease in BDNF protein levels [95] as well as a reduction in BDNF mRNA levels $[96,97]$ has been reported. A decrease in BDNF protein levels in the entorhinal and temporal cortex of AD suffers has also been described [98]. Abnormal TrkB expression of full length and truncated forms and altered distribution has been found in AD brains $[95,99]$. Ferrer et al. reported various changes in BDNF, including truncated $\operatorname{TrkB}$ and full length TrkB in glial cells, in neurons with hyperphosphorylated tau tangles and 
dystrophic neurons surrounding $\mathrm{A} \beta$ plaques from brains of individuals with severe $\mathrm{AD}$ [100].

Although the most widely studied Trk receptor is the TrkB receptor, recently Capsoni et al. (2010) reported that TrkA beneficially activates $A \beta$ accumulation in a transgenic mouse model and discusses the role of proNGF, NGF, and TrkA versus p75 neurotrophin receptor (p75NTR) in AD neurodegeneration [101].

\section{TrkB Receptors and Metals}

There have been few studies looking into a possible role for metals in TrkB signaling. Jung et al. reported that treatment of cortical neuron cultures with micromolar $\mathrm{Zn}$ concentrations can robustly activate TrkB as well as kinases downstream of the receptor, such as Src, ERK, and Akt [102]. The mechanism of $\mathrm{Zn}$ activating TrkB was found to be an extracellular one, mediated by activation of matrix metalloproteinases (MMPs) causing release of pro-BDNF by the cells, which then gets converted to mature BDNF by extracellular MMPs [93, 102]. In support of this, recently Corona [103] reported the protective role of dietary $\mathrm{Zn}$ supplementation in a transgenic mouse model of $\mathrm{AD}$, where $\mathrm{Zn}$ appeared to increase BDNF signaling by MMP activation. In vitro, in PC12 cells, $\mathrm{Zn}$ has been shown to inhibit neurite outgrowth by BDNF [104] but in cortical cultures, this inhibition was only slight, revealing that the activation by $\mathrm{Zn}$ overrides the potential BDNF/TrkB inhibitory effect [102]. Thus, $\mathrm{Zn}$ release from the glutamatergic synapse could play an important role in activity-dependant activation of TrkB.

The same group later reported that $\mathrm{Cu}$ too was able to activate TrkB in cortical neuron cultures in an MMP dependent fashion [105]. Cu, like Zn, was able to activate Src kinase, ERK, and Akt and increased the activity of MMP2 and MMP9, thereby catalyzing the conversion of pro BDNF to mature BDNF [105]. They proposed that if $\mathrm{Cu}$ is released at the synapse post-depolarisation as postulated by Hartter and Barnea then as with $\mathrm{Zn}$, there maybe physiologically beneficial effects that could be mediated by both metals, such as activation of TrkB signaling [58].

Huang et al. reported for the first time the ability of $\mathrm{Zn}$ released by stimulated CA3 hippocampal neurons to transactivate TrkB in vivo via Src kinase [106]. The activated TrkB receptors then play an important role in LTP at the mossy fiber-CA synapse. As previously discussed, TrkB receptor signaling has been reported to be important in hippocampal CA1 LTP, but this study puts forward a link between Zn, TrkB, and hippocampal CA3 LTP. With LTP known to be inhibited in $A D$, in an $A \beta$-NMDAR associated manner, assessing the $\mathrm{Zn}$, TrkB, and LTP link may provide an interesting opportunity for therapeutic intervention in AD.

\section{Membrane Receptors, Metals, and Implications for AD}

The membrane receptor systems described so far have proposed roles in $\mathrm{AD}$, and therefore metal interactions with these membrane receptor families could provide beneficial modulatory and intervention points, in the pursuit of the amelioration of $\mathrm{AD}$ pathology. Work done within our group has shown that $\mathrm{Cu}$ and $\mathrm{Zn}$, delivered into the cell by the metal chaperones CQ, PBT2, and CuGTSM, can cause activation of phosphatidylinositol 3-kinase (PI3K) and the consequent phosphorylation of Akt and GSK3 and the subsequent activation of MAPK (ERK), all kinases previously discussed as having antiapoptotic effects. This caused activation of MMP2 leading to extracellular A $\beta$ degradation [107-109].

CQ and PBT2 are 8-hydroxyquinoline metal ligands. CuGTSM belongs to the metal bisthiosemicarbazone (MBTSC) family of metal-based drugs. They are stable, of a low molecular weight, neutral and most importantly capable of crossing cell membranes [108]. Due to their versatility in vitro, their use has been widely adopted within our group. CuGTSM has demonstrated therapeutic effects in an AD mouse model and was found to affect cellular signalling pathways central to $\mathrm{AD}$ as well as the amyloid proteins, $\mathrm{A} \beta$ and tau [109].

Price et al. reported CQ coordinated to $\mathrm{Cu}$ activated epidermal growth factor receptor (EGFR) in epithelial cells and neurons [110]. This activation, by phosphorylation of EGFR, did not require EGF or TGF- $\alpha$ making it ligand independent. The phosphorylation was mediated by Src kinase and was specific for Cu. Interestingly however, activation of EGFR by CQ coordinated to $\mathrm{Cu}$ resulted in the activation of ERK only, with no effects on PI3K-Akt or JNK but still resulted in $\mathrm{A} \beta$ degradation by MMP activation. This would infer that activation of ERK by intracellular bioavailable metals is a necessary step in $\mathrm{A} \beta$ degradation, mediated by upregulation of MMP.

We later reported the EGFR activation by CuGTSM and ZnBTSCs in a glial cell line as well, but CuGTSM, in contrast to CQ coordinated to $\mathrm{Cu}$, did not phosphorylate EGFR in a Src kinase-mediated manner, rather CuGTSM inhibited the activity of protein tyrosine phosphatase (PTP). CuGTSM, as with CQ coordinated to $\mathrm{Cu}$, did however induce activation of PI3K-Akt-GSK3, ERK, and JNK [111].

Whilst EGFR has not directly been linked to AD, the pathway downstream of the receptor being activated by an increase in intracellular $\mathrm{Cu}$ and $\mathrm{Zn}$ involves kinases associated with $\mathrm{AD}$ and appears to be rather similar to TrkB signalling. Thus EGFR and its metal interactions could be an interesting area to investigate and provide clues on other possible membrane receptors affected in $\mathrm{AD}$.

\section{Conclusion}

In conclusion, an imbalance of transition metal levels in the $\mathrm{AD}$ brain plays a neurotoxic role, but how and where this imbalance affects signaling are not known. However, their interactions with membrane receptors in the glutamatergic system, TrkB and EGF signaling system, and to a lesser extent in the cholinergic system infer a potentially important effect on $\mathrm{AD}$ through these membrane receptor systems. This may involve a combination of effects including inhibitory, modulatory or activation of membrane receptor-mediated functions that have an important role in $\mathrm{AD}$. Therefore it is 
likely that the link between metals and membrane receptors may offer a unique point of intervention in $\mathrm{AD}$.

\section{Acknowledgments}

P. Amadoruge is the recipient of The George Hicks Postgraduate Scholarship for Dementia Prevention and Risk Reduction Research-Alzheimer's Australia Victoria, The George Hicks Foundation and Alzheimer's Australia Research. The authors would like to thank Dr. Anthony White for his help and review of this paper. This work was funded by the National Health and Medical Research Council of Australia and the Australian Research Council.

\section{References}

[1] A. I. Bush, "Drug development based on the metals hypothesis of Alzheimer's disease," Journal of Alzheimer's Disease, vol. 15, no. 2, pp. 223-240, 2008.

[2] R. D. Terry, E. Masliah, D. P. Salmon et al., "Physical basis of cognitive alterations in Alzheimer's disease: synapse loss is the major correlate of cognitive impairment," Annals of Neurology, vol. 30, no. 4, pp. 572-580, 1991.

[3] D. M. Walsh and D. J. Selkoe, "Oligomers in the brain: the emerging role of soluble protein aggregates in neurodegeneration," Protein and Peptide Letters, vol. 11, no. 3, pp. 213-228, 2004.

[4] Y. M. Kuo, M. R. Emmerling, C. Vigo-Pelfrey et al., "Watersoluble A $\beta(\mathrm{N}-40, \mathrm{~N}-42)$ oligomers in normal and Alzheimer disease brains," Journal of Biological Chemistry, vol. 271, no. 8, pp. 4077-4081, 1996.

[5] L. F. Lue, Y. M. Kuo, A. E. Roher et al., "Soluble amyloid $\beta$ peptide concentration as a predictor of synaptic change in Alzheimer's disease," American Journal of Pathology, vol. 155, no. 3, pp. 853-862, 1999.

[6] W. L. Klein, G. A. Krafft, and C. E. Finch, "Targeting small A $\beta$ oligomers: the solution to an Alzheimer's disease conundrum?" Trends in Neurosciences, vol. 24, no. 4, pp. 219224, 2001.

[7] J. Hardy and D. J. Selkoe, "The amyloid hypothesis of Alzheimer's disease: progress and problems on the road to therapeutics," Science, vol. 297, no. 5580, pp. 353-356, 2002.

[8] M. P. Lambert, A. K. Barlow, B. A. Chromy et al., "Diffusible, nonfibrillar ligands derived from $\mathrm{A} \beta$ are potent central nervous system neurotoxins," Proceedings of the National Academy of Sciences of the United States of America, vol. 95, no. 11, pp. 6448-6453, 1998.

[9] D. M. Walsh, I. Klyubin, J. V. Fadeeva et al., "Naturally secreted oligomers of amyloid $\beta$ protein potently inhibit hippocampal long-term potentiation in vivo," Nature, vol. 416, no. 6880, pp. 535-539, 2002.

[10] H. W. Wang, J. F. Pasternak, H. Kuo et al., "Soluble oligomers of $\beta$ amyloid (1-42) inhibit long-term potentiation but not long-term depression in rat dentate gyrus," Brain Research, vol. 924, no. 2, pp. 133-140, 2002.

[11] T. V. P. Bliss and A. R. Gardner Medwin, "Long lasting potentiation of synaptic transmission in the dentate area of the unanaesthetized rabbit following stimulation of the perforant path," Journal of Physiology, vol. 232, no. 2, pp. 357-374, 1973.

[12] P. H. Reddy, G. Mani, B. S. Park et al., "Differential loss of synaptic proteins in Alzheimer's disease: implications for synaptic dysfunction," Journal of Alzheimer's Disease, vol. 7, no. 2, pp. 103-117, 2005.

[13] M. A. Lovell, J. D. Robertson, W. J. Teesdale, J. L. Campbell, and W. R. Markesbery, "Copper, iron and zinc in Alzheimer's disease senile plaques," Journal of the Neurological Sciences, vol. 158, no. 1, pp. 47-52, 1998.

[14] C. J. Frederickson, M. A. Klitenick, W. I. Manton, and J. B. Kirkpatrick, "Cytoarchitectonic distribution of zinc in the hippocampus of man and the rat," Brain Research, vol. 273, no. 2, pp. 335-339, 1983.

[15] K. J. Barnham, C. L. Masters, and A. I. Bush, "Neurodegenerative diseases and oxidatives stress," Nature Reviews Drug Discovery, vol. 3, no. 3, pp. 205-214, 2004.

[16] A. A. A. B. White, "The metallobiology of Alzheimer's disease: from bench to clinic. Current medical literature," Neurology, vol. 22, no. 4, pp. 89-97, 2006.

[17] P. J. Crouch, K. J. Barnham, A. I. Bush, and A. R. White, "Therapeutic treatments for Alzheimer's disease based on metal bioavailability," Drug News and Perspectives, vol. 19, no. 8, pp. 469-474, 2006.

[18] M. R. Hynd, H. L. Scott, and P. R. Dodd, "Glutamatemediated excitotoxicity and neurodegeneration in Alzheimer's disease," Neurochemistry International, vol. 45, no. 5, pp. 583-595, 2004.

[19] M. Eder, K. Becker, G. Rammes et al., "Distribution and properties of functional postsynaptic kainate receptors on neocortical layer V pyramidal neurons," Journal of Neuroscience, vol. 23, no. 16, pp. 6660-6670, 2003.

[20] J. Lerma, "Roles and rules of kainate receptors in synaptic transmission," Nature Reviews Neuroscience, vol. 4, no. 6, pp. 481-495, 2003.

[21] A. S. Leonard, I. A. Lim, D. E. Hemsworth, M. C. Horne, and J. W. Hell, "Calcium/calmodulin-dependent protein kinase II is associated with the N-methyl-D-aspartate receptor," Proceedings of the National Academy of Sciences of the United States of America, vol. 96, no. 6, pp. 3239-3244, 1999.

[22] B. K. Andrásfalvy and J. C. Magee, "Changes in AMPA receptor currents following LTP induction on rat CA1 pyramidal neurones," Journal of Physiology, vol. 559, no. 2, pp. 543-554, 2004.

[23] V. Derkach, A. Barria, and T. R. Soderling, "Ca/calmodulinkinase II enhances channel conductance of $\alpha$-amino3-hydroxy-5-methyl-4-isoxazolepropionate type glutamate receptors," Proceedings of the National Academy of Sciences of the United States of America, vol. 96, no. 6, pp. 3269-3274, 1999.

[24] Z. Wang, J. G. Edwards, N. Riley et al., "Myosin Vb mobilizes recycling endosomes and AMPA receptors for postsynaptic plasticity," Cell, vol. 135, no. 3, pp. 535-548, 2008.

[25] K. U. Bayer, P. De Koninck, A. S. Leonard, J. W. Hell, and H. Schulman, "Interaction with the NMDA receptor locks CaMKII in an active conformation," Nature, vol. 411, no. 6839, pp. 801-805, 2001.

[26] P. N. Lacor, M. C. Buniel, P. W. Furlow et al., "A $\beta$ oligomerinduced aberrations in synapse composition, shape, and density provide a molecular basis for loss of connectivity in Alzheimer's disease," Journal of Neuroscience, vol. 27, no. 4, pp. 796-807, 2007.

[27] E. M. Snyder, Y. Nong, C. G. Almeida et al., "Regulation of NMDA receptor trafficking by amyloid- $\beta$," Nature Neuroscience, vol. 8, no. 8, pp. 1051-1058, 2005.

[28] A. Barria and R. Malinow, "NMDA receptor subunit composition controls synaptic plasticity by regulating binding to CaMKII," Neuron, vol. 48, no. 2, pp. 289-301, 2005. 
[29] F. Gardoni and M. Di Luca, "New targets for pharmacological intervention in the glutamatergic synapse," European Journal of Pharmacology, vol. 545, no. 1, pp. 2-10, 2006.

[30] G. E. Hardingham and H. Bading, "Coupling of extrasynaptic NMDA receptors to a CREB shut-off pathway is developmentally regulated," Biochimica et Biophysica Acta, vol. 1600, no. 1-2, pp. 148-153, 2002.

[31] C. Priller, T. Bauer, G. Mitteregger, B. Krebs, H. A. Kretzschmar, and J. Herms, "Synapse formation and function is modulated by the amyloid precursor protein," The Journal of Neuroscience, vol. 26, no. 27, pp. 7212-7221, 2006.

[32] A. Deshpande, H. Kawai, R. Metherate, C. G. Glabe, and J. Busciglio, "A role for synaptic zinc in activity-dependent $\mathrm{a} \beta$ oligomer formation and accumulation at excitatory synapses," Journal of Neuroscience, vol. 29, no. 13, pp. 40044015, 2009.

[33] B. L. Kelly and A. Ferreira, " $\beta$-amyloid-induced dynamin 1 degradation is mediated by $\mathrm{N}$-methyl-D-aspartate receptors in hippocampal neurons," Journal of Biological Chemistry, vol. 281, no. 38, pp. 28079-28089, 2006.

[34] M. Bucciantini, E. Giannoni, F. Chiti et al., "Inherent toxicity of aggregates implies a common mechanism for protein misfolding diseases," Nature, vol. 416, no. 6880, pp. 507-511, 2002.

[35] Y. J. Zhu, H. Lin, and R. Lal, "Fresh and nonfibrillar amyloid $\beta$ protein(1-40) induces rapid cellular degeneration in aged human fibroblasts: evidence for $\mathrm{A} \beta \mathrm{P}$-channel-mediated cellular toxicity," FASEB Journal, vol. 14, no. 9, pp. 1244-1254, 2000.

[36] J. I. Kourie, "Mechanisms of amyloid $\beta$ protein-induced modification in ion transport systems: implications for neurodegenerative diseases," Cellular and Molecular Neurobiology, vol. 21, no. 3, pp. 173-213, 2001.

[37] H. Hsieh, J. Boehm, C. Sato et al., "AMPAR removal underlies A $\beta$-induced synaptic depression and sendritic spine loss," Neuron, vol. 52, no. 5, pp. 831-843, 2006.

[38] C. I. Sze, H. Bi, B. K. Kleinschmidt-DeMasters, C. M. Filley, and L. J. Martin, "N-Methyl-D-aspartate receptor subunit proteins and their phosphorylation status are altered selectively in Alzheimer's disease," Journal of the Neurological Sciences, vol. 182, no. 2, pp. 151-159, 2001.

[39] A. J. Mishizen-Eberz, R. A. Rissman, T. L. Carter, M. D. Ikonomovic, B. B. Wolfe, and D. M. Armstrong, "Biochemical and molecular studies of NMDA receptor subunits $\mathrm{NR} 1 / 2 \mathrm{~A} / 2 \mathrm{~B}$ in hippocampal subregions throughout progression of Alzheimer's disease pathology," Neurobiology of Disease, vol. 15, no. 1, pp. 80-92, 2004.

[40] S. E. Hoey, R. J. Williams, and M. S. Perkinton, "Synaptic NMDA receptor activation stimulates $\alpha$-secretase amyloid precursor protein processing and inhibits amyloid- $\beta$ Production," Journal of Neuroscience, vol. 29, no. 14, pp. 4442-4460, 2009.

[41] J. Wu, R. Anwyl, and M. J. Rowan, " $\beta$-amyloid-(1-40) increases long-term potentiation in rat hippocampus," European Journal of Pharmacology, vol. 284, no. 3, pp. R1-R3, 1995.

[42] Q. S. Chen, W. Z. Wei, T. Shimahara, and C. W. Xie, "Alzheimer amyloid $\beta$-peptide inhibits the late phase of longterm potentiation through calcineurin-dependent mechanisms in the hippocampal dentate gyrus," Neurobiology of Learning and Memory, vol. 77, no. 3, pp. 354-371, 2002.

[43] S. A. Lipton, "Failures and successes of NMDA receptor antagonists: molecular basis for the use of open-channel blockers like memantine in the treatment of acute and chronic neurologic insults," NeuroRx, vol. 1, no. 1, pp. 101110, 2004.

[44] K. Vogt, J. Mellor, G. Tong, and R. Nicoll, "The actions of synaptically released zinc at hippocampal mossy fiber synapses," Neuron, vol. 26, no. 1, pp. 187-196, 2000.

[45] Y. Li, C. J. Hough, S. W. Suh, J. M. Sarvey, and C. J. Frederickson, "Rapid translocation of $\mathrm{Zn}(2+)$ from presynaptic terminals into postsynaptic hippocampal neurons after physiological stimulation," Journal of Neurophysiology, vol. 86, no. 5, pp. 2597-2604, 2001.

[46] J. Qian and J. L. Noebels, "Visualization of transmitter release with zinc fluorescence detection at the mouse hippocampal mossy fibre synapse," Journal of Physiology, vol. 566, no. 3, pp. 747-758, 2005.

[47] Y. B. Choi and S. A. Lipton, "Identification and mechanism of action of two histidine residues underlying high-affinity $\mathrm{Zn}^{2+}$ inhibition of the NMDA receptor," Neuron, vol. 23, no. 1, pp. 171-180, 1999.

[48] P. Paoletti, F. Perin-Dureau, A. Fayyazuddin, A. Le Goff, I. Callebaut, and J. Neyton, "Molecular organization of a zinc binding N-terminal modulatory domain in a NMDA receptor subunit," Neuron, vol. 28, no. 3, pp. 911-925, 2000.

[49] J. Rachline, F. Perin-Dureau, A. Le Goff, J. Neyton, and P. Paoletti, "The micromolar zinc-binding domain on the NMDA receptor subunit NR2B," Journal of Neuroscience, vol. 25, no. 2, pp. 308-317, 2005.

[50] P. Paoletti, P. Ascher, and J. Neyton, "High-affinity zinc inhibition of NMDA NR1-NR2A receptors," Journal of Neuroscience, vol. 17, no. 15, pp. 5711-5725, 1997.

[51] M. L. Mayer, L. Vyklicky, and G. L. Westbrook, "Modulation of excitatory amino acid receptors by group IIB metal cations in cultured mouse hippocampal neurones," Journal of Physiology, vol. 415, pp. 329-350, 1989.

[52] S. Peters, J. Koh, and D. W. Choi, "Zinc selectively blocks the action of N-methyl-D-aspartate on cortical neurons," Science, vol. 236, no. 4801, pp. 589-593, 1987.

[53] G. L. Westbrook and M. L. Mayer, "Micromolar concentrations of $\mathrm{Zn}^{2+}$ antagonize NMDA and GABA responses of hippocampal neurons," Nature, vol. 328, no. 6131, pp. 640643, 1987.

[54] Y. Li, C. J. Hough, C. J. Frederickson, and J. M. Sarvey, "Induction of mossy fiber $\rightarrow$ CA3 long-term potentiation requires translocation of synaptically released $\mathrm{Zn}^{2+}$," Journal of Neuroscience, vol. 21, no. 20, pp. 8015-8025, 2001.

[55] C. B. Sindreu, H. Varoqui, J. D. Erickson, and J. PérezClausell, "Boutons containing vesicular zinc define a subpopulation of synapses with low AMPAR content in rat hippocampus," Cerebral Cortex, vol. 13, no. 8, pp. 823-829, 2003.

[56] M. L. Schlief and J. D. Gitlin, "Copper homeostasis in the CNS: a novel link between the NMDA receptor and copper homeostasis in the hippocampus," Molecular Neurobiology, vol. 33, no. 2, pp. 81-90, 2006.

[57] M. L. Schlief, A. M. Craig, and J. D. Gitlin, "NMDA receptor activation mediates copper homeostasis in hippocampal neurons," Journal of Neuroscience, vol. 25, no. 1, pp. 239-246, 2005.

[58] D. E. Hartter and A. Barnea, "Evidence for release of copper in the brain: depolarization-induced release of newly takenup copper," Synapse, vol. 2, no. 4, pp. 412-415, 1988.

[59] J. Kardos, I. Kovacs, F. Hajos, M. Kalman, and M. Simonyi, "Nerve endings from rat brain tissue release copper upon depolarization. A possible role in regulating neuronal 
excitability," Neuroscience Letters, vol. 103, no. 2, pp. 139-144, 1989.

[60] K. J. Barnham and A. I. Bush, "Metals in Alzheimer's and Parkinson's diseases," Current Opinion in Chemical Biology, vol. 12, no. 2, pp. 222-228, 2008.

[61] P. Dutar, M. H. Bassant, M. C. Senut, and Y. Lamour, "The septohippocampal pathway: structure and function of a central cholinergic system," Physiological Reviews, vol. 75, no. 2, pp. 393-427, 1995.

[62] J. Winkler, S. T. Suhr, F. H. Gage, L. J. Thal, and L. J. Fisher, "Essential role of neoecortical acetylcholine in spatial memory," Nature, vol. 375, no. 6531, pp. 484-487, 1995.

[63] R. T. Bartus, R. L. Dean, B. Beer, and A. S. Lippa, "The cholinergic hypothesis of geriatric memory dysfunction," Science, vol. 217, no. 4558, pp. 408-417, 1982.

[64] J. T. Coyle, D. L. Price, and M. R. DeLong, "Alzheimer's disease: a disorder of cortical cholinergic innervation," Science, vol. 219, no. 4589, pp. 1184-1190, 1983.

[65] M. Goedert, "Tau protein and the neurofibrillary pathology of Alzheimer's disease," Trends in Neurosciences, vol. 16, no. 11, pp. 460-465, 1993.

[66] E. K. Perry, M. Johnson, J. M. Kerwin et al., "Convergent cholinergic activities in aging and Alzheimer's disease," Neurobiology of Aging, vol. 13, no. 3, pp. 393-400, 1992.

[67] G. Ransmayr, P. Cervera, E. C. Hirsch, W. Berger, W. Fischer, and Y. Agid, "Alzheimer's disease: is the decrease of the cholinergic innervation of the hippocampus related to intrinsic hippocampal pathology?" Neuroscience, vol. 47, no. 4, pp. 843-851, 1992.

[68] L. M. Bierer, V. Haroutunian, S. Gabriel et al., "Neurochemical correlates of dementia severity in Alzheimer's disease: relative importance of the cholinergic deficits," Journal of Neurochemistry, vol. 64, no. 2, pp. 749-760, 1995.

[69] R. S. Jope, L. Song, and R. E. Powers, "Cholinergic activation of phosphoinositide signaling is impaired in Alzheimer's disease brain," Neurobiology of Aging, vol. 18, no. 1, pp. 111120, 1997.

[70] C. J. Ladner and J. M. Lee, "Pharmacological drug treatment of Alzheimer disease: the cholinergic hypothesis revisited," Journal of Neuropathology and Experimental Neurology, vol. 57, no. 8, pp. 719-731, 1998.

[71] W. A. Pedersen, M. A. Kloczewiak, and J. K. Blusztajn, "Amyloid $\beta$-protein reduces acetylcholine synthesis in a cell line derived from cholinergic neurons of the basal forebrain," Proceedings of the National Academy of Sciences of the United States of America, vol. 93, no. 15, pp. 8068-8071, 1996.

[72] S. Boncristiano, M. E. Calhoun, P. H. Kelly et al., "Cholinergic changes in the APP23 transgenic mouse model of cerebral amyloidosis," Journal of Neuroscience, vol. 22, no. 8, pp. 32343243, 2002.

[73] D. M. Bowen, C. B. Smith, P. White, and A. N. Davison, "Neurotransmitter related enzymes and indices of hypoxia in senile dementia and other abiotrophies," Brain, vol. 99, no. 3, pp. 459-496, 1976.

[74] P. J. Whitehouse, D. L. Price, and R. G. Struble, “Alzheimer's disease and senile dementia: loss of neurons in the basal forebrain," Science, vol. 215, no. 4537, pp. 1237-1239, 1982.

[75] O. J. M. Vogels, C. A. J. Broere, H. J. Ter Laak, H. J. Ten Donkelaar, R. Nieuwenhuys, and B. P. M. Schulte, "Cell loss and shrinkage in the nucleus basalis Meynert complex in Alzheimer's disease," Neurobiology of Aging, vol. 11, no. 1, pp. 3-13, 1990.

[76] H. Y. Wang, D. H. S. Lee, M. R. D’Andrea, P. A. Peterson, R. P. Shank, and A. B. Reitz, " $\beta$-amyloid binds to $\alpha 7$ nicotinic acetylcholine receptor with high affinity. Implications for Alzheimer's disease pathology," Journal of Biological Chemistry, vol. 275, no. 8, pp. 5626-5632, 2000.

[77] H. Y. Wang, D. H. S. Lee, C. B. Davis, and R. P. Shank, "Amyloid peptide $A \beta(1-42)$ binds selectively and with picomolar affinity to $\alpha 7$ nicotinic acetylcholine receptors," Journal of Neurochemistry, vol. 75, no. 3, pp. 1155-1161, 2000.

[78] H. Y. Wang, A. Stucky, J. Liu, C. Shen, C. Trocme-Thibierge, and P. Morain, "Dissociating $\beta$-amyloid from $\alpha 7$ nicotinic acetylcholine receptor by a novel therapeutic agent, S 24795, normalizes $\alpha 7$ nicotinic acetylcholine and NMDA receptor function in Alzheimer's disease brain," Journal of Neuroscience, vol. 29, no. 35, pp. 10961-10973, 2009.

[79] L. G. Costa and D. A. Fox, "A selective decrease of cholinergic muscarinic receptors in the visual cortex of adult rats following developmental lead exposure," Brain Research, vol. 276, no. 2, pp. 259-266, 1983.

[80] G. V. W. Johnson and R. S. Jope, "Aluminum impairs glucose utilization and cholinergic activity in rat brain in vitro," Toxicology, vol. 40, no. 1, pp. 93-102, 1986.

[81] W. S. Webster and A. A. Valois, "The toxic effects of cadmium on the neonatal mouse CNS," Journal of Neuropathology and Experimental Neurology, vol. 40, no. 3, pp. 247-257, 1981.

[82] C. Winder and I. Kitchen, "Lead neurotoxicity: a review of the biochemical, neurochemical and drug induced behavioural evidence," Progress in Neurobiology, vol. 22, no. 1, pp. 59-87, 1984.

[83] P. Moingeon, J. M. Bidart, and G. F. Alberici, "In vivo modulation of muscarine receptors in rat brain by acute lead intoxication," Toxicology, vol. 31, no. 2, pp. 135-142, 1984.

[84] S. Schulte, W. E. Müller, and K. D. Friedberg, "In vivo exposure to lead does not influence muscarinic receptors in the frontal cortex of the mouse brain," Toxicology, vol. 93, no. 2-3, pp. 99-112, 1994.

[85] C. Gotti, D. Cabrini, E. Sher, and F. Clementi, "Effects of long-term in vitro exposure to aluminum, cadmium or lead on differentiation and cholinergic receptor expression in a human neuroblastoma cell line," Cell Biology and Toxicology, vol. 3, no. 4, pp. 431-440, 1987.

[86] G. R. Lewin and Y. A. Barde, "Physiology of the neurotrophins," Annual Review of Neuroscience, vol. 19, pp. 289317, 1996.

[87] E. S. Levine, C. F. Dreyfus, I. B. Black, and M. R. Plummer, "Brain-derived neurotrophic factor rapidly enhances synaptic transmission in hippocampal neurons via postsynaptic tyrosine kinase receptors," Proceedings of the National Academy of Sciences of the United States of America, vol. 92, no. 17, pp. 8074-8077, 1995.

[88] H. Kang and E. M. Schuman, "Long-lasting neuratrophininduced enhancement of synaptic transmission in the adult hippocampus," Science, vol. 267, no. 5204, pp. 1658-1662, 1995.

[89] G. Chen, R. Kolbeck, Y. A. Barde, T. Bonhoeffer, and A. Kossel, "Relative contribution of endogenous neurotrophins in hippocampal long- term potentiation," Journal of Neuroscience, vol. 19, no. 18, pp. 7983-7990, 1999.

[90] A. H. Kossel, S. B. Cambridge, U. Wagner, and T. Bonhoeffer, "A caged Ab reveals an immediate/instructive effect of BDNF during hippocampal synaptic potentiation," Proceedings of the National Academy of Sciences of the United States of America, vol. 98, no. 25, pp. 14702-14707, 2001.

[91] M. Barbacid, "Structural and functional properties of the TRK family of neurotrophin receptors," Annals of the New York Academy of Sciences, vol. 766, pp. 442-458, 1995. 
[92] E. J. Huang and L. F. Reichardt, "Trk receptors: roles in neuronal signal transduction," Annual Review of Biochemistry, vol. 72, pp. 609-642, 2003.

[93] R. Lee, P. Kermani, K. K. Teng, and B. L. Hempstead, "Regulation of cell survival by secreted proneurotrophins," Science, vol. 294, no. 5548, pp. 1945-1948, 2001.

[94] F. S. Lee, R. Rajagopal, A. H. Kim, P. C. Chang, and M. V. Chao, "Activation of Trk neurotrophin receptor signaling by pituitary adenylate cyclase-activating polypeptides," Journal of Biological Chemistry, vol. 277, no. 11, pp. 9096-9102, 2002.

[95] B. Connor, D. Young, Q. Yan, R. L. M. Faull, B. Synek, and M. Dragunow, "Brain-derived neurotrophic factor is reduced in Alzheimer's disease," Molecular Brain Research, vol. 49, no. 12, pp. 71-81, 1997.

[96] H. S. Phillips, J. M. Hains, M. Armanini, G. R. Laramee, S. A. Johnson, and J. W. Winslow, "BDNF mRNA is decreased in the hippocampus of individuals with Alzheimer's disease," Neuron, vol. 7, no. 5, pp. 695-702, 1991.

[97] K. D. Murray, C. M. Gall, E. G. Jones, and P. J. Isackson, "Differential regulation of brain-derived neurotrophic factor and type II calcium/calmodulin-dependent protein kinase messenger RNA expression in Alzheimer's disease," Neuroscience, vol. 60, no. 1, pp. 37-48, 1994.

[98] M. Narisawa-Saito, K. Wakabayashi, S. Tsuji, H. Takahashi, and H. Nawa, "Regional specificity of alterations in NGF, BDNF and NT-3 levels in Alzheimer's disease," NeuroReport, vol. 7, no. 18, pp. 2925-2928, 1996.

[99] A. Salehi, J. Verhaagen, P. A. Dijkhuizen, and D. F. Swaab, "Co-localization of high-affinity neurotrophin receptors in nucleus basalis of Meynert neurons and their differential reduction in Alzheimer's disease," Neuroscience, vol. 75, no. 2, pp. 373-387, 1996.

[100] I. Ferrer, C. Marín, M. J. Rey et al., "BDNF and full-length and truncated TrkB expression in Alzheimer disease. Implications in therapeutic strategies," Journal of Neuropathology and Experimental Neurology, vol. 58, no. 7, pp. 729-739, 1999.

[101] S. Capsoni, C. Tiveron, D. Vignone, G. Amato, and A. Cattaneo, "Dissecting the involvement of tropomyosinrelated kinase A and p75 neurotrophin receptor signaling in NGF deficit-induced neurodegeneration," Proceedings of the National Academy of Sciences of the United States of America, vol. 107, no. 27, pp. 12299-12304, 2010.

[102] J. H. Jung, M. H. Park, S. Y. Choi, and J. Y. Koh, “Activation of the Trk signaling pathway by extracellular zinc. Role of metalloproteinases," Journal of Biological Chemistry, vol. 280, no. 12, pp. 11995-12001, 2005.

[103] C. E. A. Corona, "Dietary zinc supplementation of 3xTg-AD mice increases BDNF levels and prevents cognitive deficits as well as mitochondrial dysfunction," Cell Death and Disease, vol. 1, article e91, 2010.

[104] G. M. Ross, I. L. Shamovsky, G. Lawrance et al., "Zinc alters conformation and inhibits biological activities of nerve growth factor and related neurotrophins," Nature Medicine, vol. 3, no. 8, pp. 872-878, 1997.

[105] J. H. Jung, MI. H. Park, and J. Y. Koh, "Copper activates TrkB in cortical neurons in a metalloproteinase-dependent manner," Journal of Neuroscience Research, vol. 85, no. 10, pp. 2160-2166, 2007.

[106] Y. Z. Huang, E. Pan, Z. Q. Xiong, and J. O. McNamara, "Zincmediated transactivation of TrkB potentiates the hippocampal mossy fiber-CA3 pyramid synapse," Neuron, vol. 57, no. 4, pp. 546-558, 2008.
[107] A. R. White, T. Du, K. M. Laughton et al., "Degradation of the Alzheimer disease amyloid $\beta$-peptide by metaldependent up-regulation of metalloprotease activity," Journal of Biological Chemistry, vol. 281, no. 26, pp. 17670-17680, 2006.

[108] P. S. Donnelly, A. Caragounis, T. Du et al., "Selective intracellular release of copper and zinc ions from bis(thiosemicarbazonato) complexes reduces levels of Alzheimer disease amyloid- $\beta$ peptide," Journal of Biological Chemistry, vol. 283, no. 8, pp. 4568-4577, 2008.

[109] P. J. Crouch, W. H. Lin, P. A. Adlard et al., "Increasing $\mathrm{Cu}$ bioavailability inhibits $\mathrm{A} \beta$ oligomers and tau phosphorylation," Proceedings of the National Academy of Sciences of the United States of America, vol. 106, no. 2, pp. 381-386, 2009.

[110] K. A. Price, G. Filiz, A. Caragounis et al., "Activation of epidermal growth factor receptor by metal-ligand complexes decreases levels of extracellular amyloid beta peptide," International Journal of Biochemistry and Cell Biology, vol. 40, no. 9, pp. 1901-1917, 2008.

[111] K. A. Price, A. Caragounis, B. M. Paterson et al., "Sustained activation of glial cell epidermal growth factor receptor by bis(thiosemicarbazonato) metal complexes is associated with inhibition of protein tyrosine phosphatase activity," Journal of Medicinal Chemistry, vol. 52, no. 21, pp. 6606-6620, 2009. 


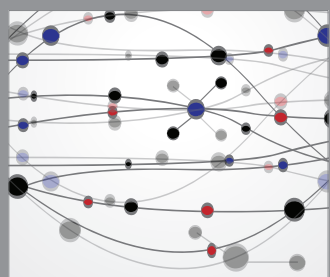

The Scientific World Journal
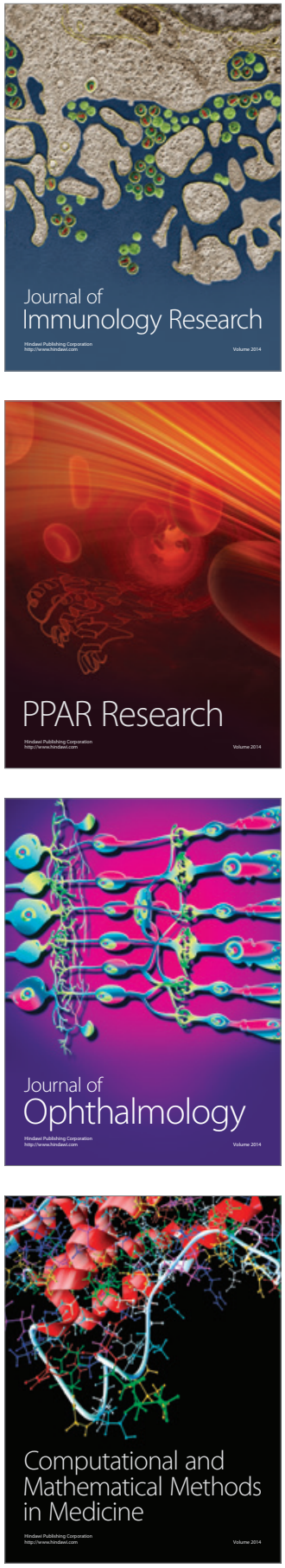

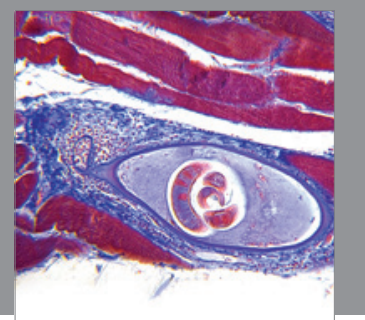

Gastroenterology

Research and Practice
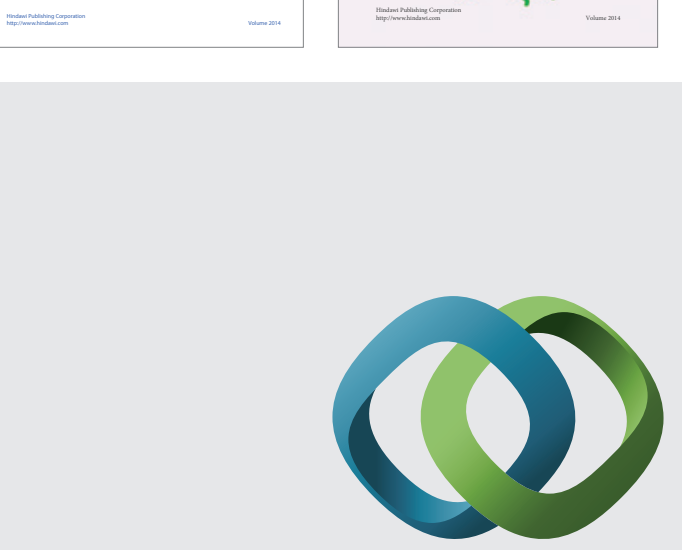

\section{Hindawi}

Submit your manuscripts at

http://www.hindawi.com
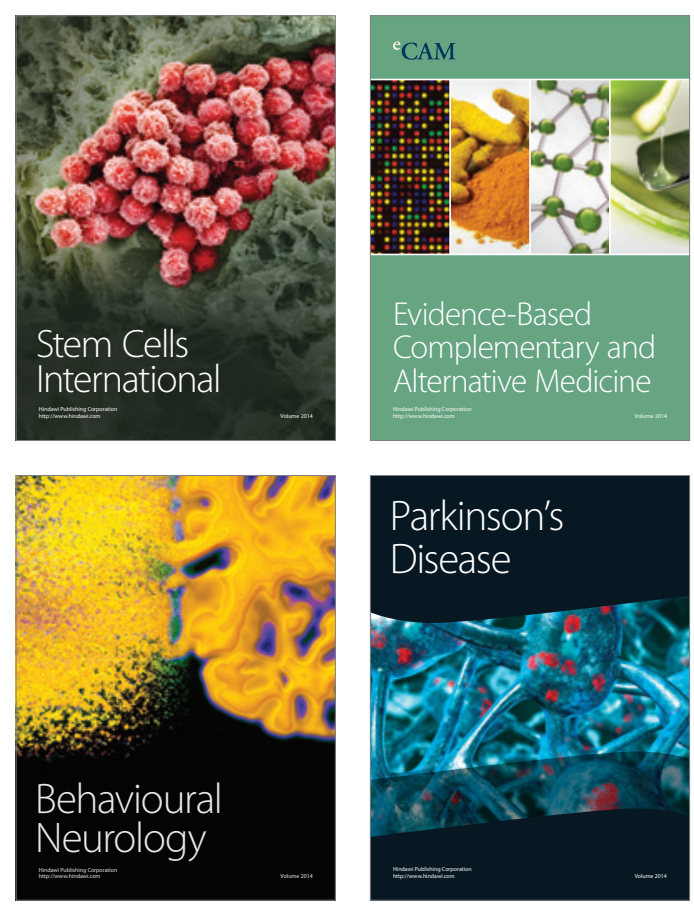

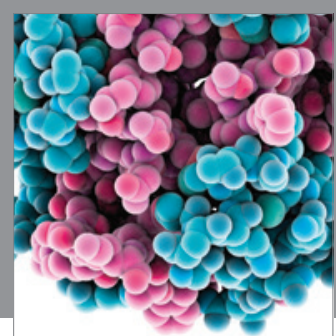

Journal of
Diabetes Research

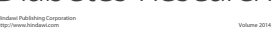

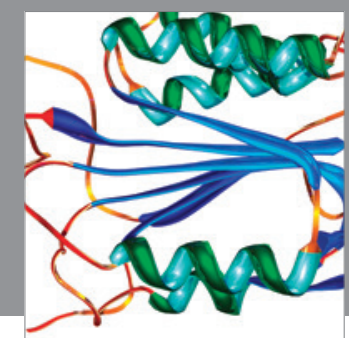

Disease Markers
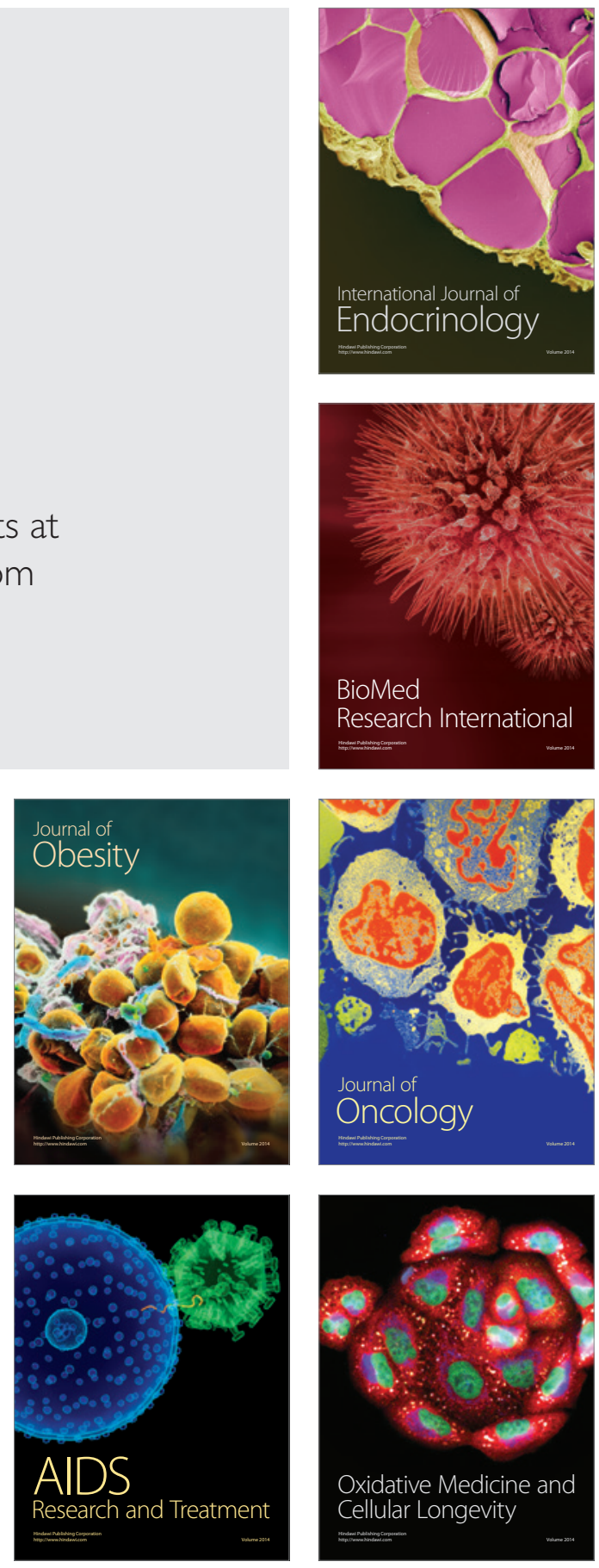